\title{
Climate Science Reconsidered
}

\author{
Chris Rapley and Kris De Meyer
}

There is a gap between the current role of the climate science community and the needs of society. Closing this gap represents a necessary but insufficient step towards improved public discourse and more constructive policy formulation on climate change.

How should climate scientists balance their efforts between investigating the climate system and engaging with policy-makers and the public? When engaging, should they merely aim to inform policy, or should they advocate specific actions? In a newly published study ${ }^{1}$ we argue that these questions are unresolved, and that there is a gap between the role of the climate science community and the needs of society. The implications of climate science merit widespread constructive and thoughtful discussion. Yet the public discourse is commonly fraught with contention, and climate scientists often find themselves on the receiving end of emotionally-charged reactions to their work. To turn this situation around, we encourage the community to reconsider its professional practices, skills and norms, and to adjust its training and development activities accordingly.

This is not the first time such a call has been issued. In 1997, Jane Lubchenco then newly appointed as President of the American Association for the Advancement of Science - delivered a speech ${ }^{2}$ in which she underscored the extent of the human impacts on the ecological systems of the planet and the intimate connections of these systems with human health, the economy, social justice, and national security. She saw it as incumbent on researchers to reflect on the nature of their responsibilities to society, and to evaluate the extent to which they were fulfilling them. She invited the science community to "participate vigorously in exploring the relationship between science and society and in considering a New Social Contract for Science as we enter the Century of the Environment".

In the event, the 'vigorous exploration' did not materialize. We suggest in the report that this is due in part to a rapid increase in research responsibilities, which, albeit with exceptions, has led busy individuals to focus on their science rather than to take on additional commitments in the areas of public discourse and policy. More fundamentally, there is a lack of a formal mechanism by which climate scientists can discuss these issues or receive training for roles that are additional to their scientific research. To overcome this, we recommend the establishment of a professional body as a means to identify and establish professional norms, values and practices appropriate to societal needs. Initial reactions from climate scientists have ranged from somewhat dismissive to suggestions of existing bodies that might take on the task. Given the wide range of disciplines that contribute to climate science, and its international nature, a 
'grand alliance' of existing bodies may well offer the way forward. The discussion on pros, cons and alternatives is ongoing.

Building on the work of Roger Pielke $\mathrm{Jnr}^{3}$, we identify five idealized roles that climate scientists may adopt. Although a climate scientist does not need to adopt all five of the roles, it is important that individuals are clear about the role they take on in different contexts, and how the balance of roles executed by the community as a whole addresses the needs of society.

The 'Pure Scientist' focuses on generating 'facts' to advance knowledge with no consideration for their use and no direct connection with decision-makers. The 'Science Arbiter' answers questions posed by decision-makers but does not delve into policy considerations, taking care to limit responses to the positive (factual) rather than the normative (value-laden) domain. Then there is the 'Science Communicator' who engages with society to present the scientific results, to offer expert interpretation, and to draw attention to the implications. The 'Honest Broker of Policy Alternatives' contributes scientific expertise to climate-related decision-making, along with other stakeholders, to ensure that available choices are fully explored and evaluated. This fits well into a process of 'co-production' in which policy-makers and the public agree on a way forward, supported by the best available scientific knowledge. Finally, there is the 'Issue Advocate' who engages with decision-makers and the public to promote a particular course of action, justified on the basis of their expert knowledge and understanding.

Of the five roles, the 'pure scientist' is the primary focus of the majority of researchers. It is often what attracted them to the academic research profession in the first place, and generally provides their greatest source of job satisfaction. Many would argue that, given commitments of teaching, supporting peer review, and a multitude of administrative tasks, this role represents the limit of a researcher's capability and obligation.

Most would also argue that the research role is, by and large, well-executed. However, in the report we draw attention to insights from the mind and behavioural sciences that call into question the extent to which the scientific ideals of impartiality and rationality are always achieved in practice. For instance, there exists a general lack of appreciation of the potential for every one of us to suffer 'myside bias', the propensity to see only one's own side of an argument. Confirmation biases in science may be common ${ }^{4}$, as are group dynamics apparent in the way scientific communities operate ${ }^{5}$. However, as Karl Popper observed, these vulnerabilities do not invalidate the scientific process itself as "It is not the objectivity or detachment of the individual scientist, but of science itself (what may be called the "friendly-hostile cooperation of scientists" - that is, their readiness for mutual criticism) which makes for objectivity"6. The very broad nature of climate science, in which no individual is an expert on all of its details, places a premium on the effectiveness of this process. We suggest that by drawing upon the talents and efforts of people outside the climate science 
community - scientists from other disciplines, statisticians, and the public at large - the scrutiny of the scientific process can be strengthened. If done publicly and transparently - e.g., via the internet - it can inspire trust, and generate public interest, as well as increasing the robustness of the scientific results.

Regarding the role of science communicator, we agree with Corner and Groves ${ }^{7}$ about the benefit of using personalized story-telling in order to better engage different audiences, and on the need for a forum for active public discussion. A consistent core narrative is needed that is accurate, engaging and coherent. It is important that it makes clear what is known and unknown, in order that ongoing scientific developments can be seen for what they are - the natural advancement of scientific knowledge and understanding.

Regarding the 'Science Arbiter' and 'Honest Broker' roles, we recognize the danger emphasized by Pielke of 'stealth issue advocacy'. When adopting these roles, climate scientists should only seek to respond to positive, not normative questions. Science can illuminate, but not arbitrate, political decisions. Given this, and given the potential loss of trust if their impartiality is perceived to be compromised, many climate scientists abstain from the 'Issue Advocate' role, in which prescriptive actions are promoted. Others, however, argue that a climate scientist's specialist knowledge, acquired at the tax-payers' expense, constitutes an obligation to speak out. The decision to do so lies with the individual, as does the responsibility to make clear when they are acting as an informed citizen rather than a professional scientist.

More fundamentally, we encourage the climate science community to abandon the "linear model'8 in which "science speaks truth to power", and adopt a coproduction approach in which scientists take their place with other experts and members of the public, offering input as appropriate to the decision-making process. This would remove climate science from the direct firing line, which it currently occupies, leaving the authority, responsibility and accountability for decisions transparently where they belong - with the policy-makers and the public. The challenge of such an approach would be to overcome widespread established practices, in which the 'linear model' continues to prevail.

Finally, taking to heart the insights from the mind sciences, in the report we recommend that "Active critical self-reflection and humility should become the evident and habitual cultural norm on the part of all participants in the climate discourse. We need to be vigilant in scrutinizing how we evaluate evidence and judge others. We are all less rational and more rationalizing than we think". Setting an example, we responded swiftly to criticism about jargon in the report's summary recommendations by rewriting the web version in plain language ${ }^{8}$.

Chris Rapley is in the Department of Earth Sciences, University College London, Gower Street, London WC1E 6BT; Kris De Meyer is in the Department of Informatics, Kings College London, Strand, London WC2R 2LS. 


\section{Email: christopher.rapley@ucl.ac.uk}

\section{References}

1 Rapley, C. G., De Meyer, K., Carney, J., Clarke, R., Howarth, C., Smith, N., Stilgoe, J., Youngs, S., Brierley, C., Haugvaldstad, A., Lotto, B., Michie, S., Shipworth, M., and Tuckett, D. Time for Change? Climate Science Reconsidered. Report of the UCL Policy Commission on Communicating Climate Science (2014).

2 Lubchenco, J. Entering the Century of the environment: A new social contract for science. Science 279, 491-497 (1998).

3 Pielke Jr, R. A. The Honest Broker: Making Sense of Science in Policy and Politics. (Cambridge University Press, 2007).

4 Mahoney, M. J. Psychology of the Scientist: An Evaluative Review. Social Studies of Science 9, 349-375 (1979).

5 Kuhn, T. S. The structure of scientific revolutions. (The University of Chicago Press, 1962).

6 Popper, K. R. The Myth of the Framework - In Defence of Science and Rationality. (Routeledge, 1994).

7 Corner, A., and Groves. Breaking the climate change communication deadlock. Nature Climate Change (2014).

8 Hulme, M. Why We Disagree About Climate Change. (Cambridge University Press, 2009).

8 http://www.ucl.ac.uk/public-policy/Policy_Commissions/Communicationclimate-science

(1356w) 